Sadia Qayyum, Ke Meng, Sidra Pervez, Faiza Nawaz and Changsheng Peng*

\title{
Optimization of $\mathrm{pH}$, temperature and carbon source for bioleaching of heavy metals by Aspergillus flavus isolated from contaminated soil
}

https://doi.org/10.1515/mgmc-2018-0038

Received July 17, 2018; accepted October 14, 2018

\begin{abstract}
Soil contamination with heavy metal content is a growing concern throughout the world as a result of industrial, mining, agricultural and domestic activities. Fungi are the most common and efficient group of heavy metal resistant microbe family which have potential for metal bioleaching. The use of filamentous fungi in bioleaching of heavy metals from contaminated soil has been developed recently. The current study intends to isolate a strain with the ability to degrade the $\mathrm{pH}$ value of the liquid medium. Identification results based on morphological and molecular biological analysis gave a 98\% match to Aspergillus flavus. Batch experiments were conducted to select the optimal conditions for bioleaching process which indicated that $130 \mathrm{mg} / \mathrm{L}$ sucrose, neutral $\mathrm{pH}$ and temperature of $30^{\circ} \mathrm{C}$ were more suitable during 15-day bioleaching experiments using A. flavus. In onestep bioleaching, the bioleaching efficiencies were $18.16 \%$ for $\mathrm{Pb}, 39.77 \%$ for $\mathrm{Cd}$ and $58.22 \%$ for $\mathrm{Zn}^{+2}$, while two-step bioleaching showed efficiencies of $16.91 \%$ for $\mathrm{Pb}, 49.66 \%$ for $\mathrm{Cd}$ and $65.73 \%$ for $\mathrm{Zn}^{+2}$. Overall, this study indicates that bioleaching of heavy metals in contaminated soil using A. flavus has the potential for contaminated soil remediation.
\end{abstract}

Keywords: Aspergillus flavus; bioleaching; contaminated soil; fungi; heavy metals.

\footnotetext{
*Corresponding author: Changsheng Peng, The Key Laboratory of Marine Environmental Science and Ecology, Ministry of Education, Ocean University of China, Qingdao 266100, China; and State Key Laboratory of Environmental Criteria and Risk Assessment, Chinese Research Academy of Environmental Sciences, Beijing 100012, China, e-mail:pcs005@ouc.edu.cn

Sadia Qayyum: The Key Laboratory of Marine Environmental Science and Ecology, Ministry of Education, Ocean University of China, Qingdao 266100, China; and Department of Microbiology, Hazara University, Mansehra 23100, Pakistan

Ke Meng: The Key Laboratory of Marine Environmental Science and Ecology, Ministry of Education, Ocean University of China, Qingdao 266100, China

Sidra Pervez and Faiza Nawaz: Department of Microbiology, Hazara University, Mansehra 23100, Pakistan
}

\section{Introduction}

Due to high industrial expansion, large quantities of industrial wastes have been generated and improperly disposed without prior special treatments. Soil contaminated with heavy metals has recently become a serious concern in China and other parts of the world (Vega et al., 1994; Leštan et al., 2008). Unlike many other pollutants, heavy metals are difficult to remove from the environment. These metals cannot be chemically or biologically degraded and are ultimately indestructible. Their transportation and accumulation in agricultural products pose a risk to food safety and human health (Dowdy and Volk, 1983). According to some reports, each year heavy metal contamination affects $100000 \mathrm{~km}^{2}$ of cultivated land and $12 \mathrm{Mt}$ of grain in China (Wang and Ma, 2008). Throughout the world heavy metal pollution of soil is still a thoroughly unsolved environmental problem, and reliable remediation techniques are required for removal of toxic heavy metals.

Various physical and chemical techniques have been developed for removal of metals from contaminated soils such as electrokinetics, solidification/stabilization and extraction techniques (Gilbert and Wey, 1990; Hong et al., 1999; Walker et al., 2003; Rebele and Lehmann, 2011). Although these techniques have widely been applied in practice, disadvantages of these methods have been reported in several studies (Ok et al., 2011). By application of solidification method, heavy metal precipitation occurs in the soil with decrease in their bioavailability and mobility, but the remaining precipitates in the soil can be solubilized through change in soil environment; therefore, solidification may be a reason for secondary pollution. In extraction processes, chelators were mostly used; like the use of synthetic chelators such as ethylenediamine-tetraacetic acid in soil results in the improvement of both solubility and bioavailability of heavy metals. However, excessive use of chemical chelates resulted to pollution of the ground water and negatively affected soil quality as many necessary ions are also chelated unselectively. Hence, a simple and economically feasible technology is required for removal of heavy metals from contaminated soils. 
Currently, a promising cost-effective alternative bioleaching approach for the removal of heavy metals from contaminated soils can be more effective (Chen and Lin, 2010; Ko et al., 2013; Govarthanan et al., 2014) than other physical or chemical technologies. Filamentous fungi show capacity to leach metals from different substances by the production of weak organic acids that form water-soluble complexes with metals (More et al., 2010). Several species of fungi, especially Aspergillus and Penicillium, have been reported for bioleaching of heavy metals in soils, such as Aspergillus niger and Penicillium simplicissimum (Ren et al., 2009; Amiri et al., 2011; Deng et al., 2012). In the process of bioleaching, low molecular weight metabolites including oxalic acid, succinic acid, citric acid, malic acid, gluconic acid and pyruvic acid can be responsible for the bioleaching mechanism (Ren et al., 2009) because fungi adopt an absorptive mode of nutrition by producing different kinds of digestive enzymes, so when these enzymes and organic acids are produced by fungi then they can extract high concentration of metal in their biomass, which results in lowering the toxicity of heavy metals. Additionally, the potential of fungi taken from contaminated fields is that the organism adopts that indigenous environment by developing survival mechanisms, and such organisms can be used as bioremediation tools in the future. Although the process of bioleaching used in remediation of heavy metal contaminated soils seems potential, few studies have been performed. Therefore, the objectives of the present study are (1) to select a heavy metal resistant strain with the ability to produce many organic acids and (2) to select the best optimal conditions for bioleaching.

\section{Results and discussion}

\section{Soil characteristics}

Physio-chemical characteristics of contaminated soil and the comparisons of heavy metal concentrations between experimental soil and the secondary soil environmental quality standard are presented in Table 1 . Very high

Table 1: Physio-chemical characteristics of the soil.

\begin{tabular}{|c|c|c|c|c|c|c|}
\hline $\mathrm{pH}$ & $\begin{array}{r}\mathrm{EC} \\
(\mathrm{ms} \cdot \mathrm{cm})\end{array}$ & $\begin{array}{r}\text { Clay } \\
(\%)\end{array}$ & & $\begin{array}{r}\mathrm{Zn}^{+2} \\
\left(\mathrm{mg} \cdot \mathrm{kg}^{-1}\right)\end{array}$ & $\begin{array}{r}\mathrm{Pb} \\
\left(\mathrm{mg} \cdot \mathrm{kg}^{-1}\right)\end{array}$ & $\begin{array}{r}\mathrm{Cd} \\
\left(\mathrm{mg} \cdot \mathrm{kg}^{-1}\right)\end{array}$ \\
\hline \multirow[t]{2}{*}{8.03} & 3 & 38.7 & Soil & 9860 & 4720 & 276 \\
\hline & & & Standard & 300 & 350 & 1 \\
\hline
\end{tabular}

EC, Electrical conductivity. concentration of heavy metals in these samples show major hazards for aquatic environment and human health.

\section{Fungal isolation and screening}

Six tolerant fungi strains (F1-F6) were transplanted to sucrose medium individually; $\mathrm{pH}$ variations of the media are shown in Figure 1. During 8 days of inoculation, F3 decreased the $\mathrm{pH}$ value from 5.71 to 3.03 , whereas the other five strains did not lead to significant degradation of $\mathrm{pH}$ values. This means that $\mathrm{F} 3$ had the ability to produce many organic acids which were then used to remove soil heavy metals (Valix et al., 2001; Mulligan and Cloutier, 2003; Qayyum et al., 2016).

\section{Fungal identification}

The morphological analysis of strain $\mathrm{F} 3$ shows the morphology of both colonies and mycelia (Figure 2). The surface is greenish-yellow to olive and may have a white border. The texture is often floccose, especially near the center, and overall can be velvety to woolly. Tan to yellowish reverse on Sabouraud Dextrose media which were identical with Aspergillus flavus (Kurniati et al., 2014). Thus, the morphological study of Aspergillus spp. had some distinguishable characteristics and the discrimination of these characteristics was very difficult by microscopic investigation. On the other hand, ITS (internal transcribed spacer) based PCR identification techniques provided highly useful information about the molecular identification and distinction of fungi, especially closely related fungi (Rasime et al., 2013). The ITS sequence of

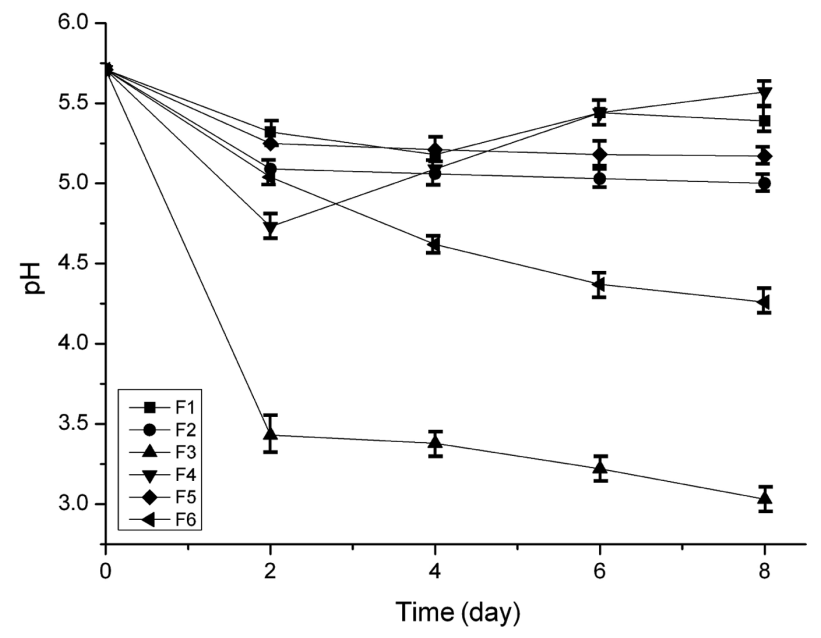

Figure 1: $\mathrm{pH}$ variations in sucrose medium of isolated fungi. 


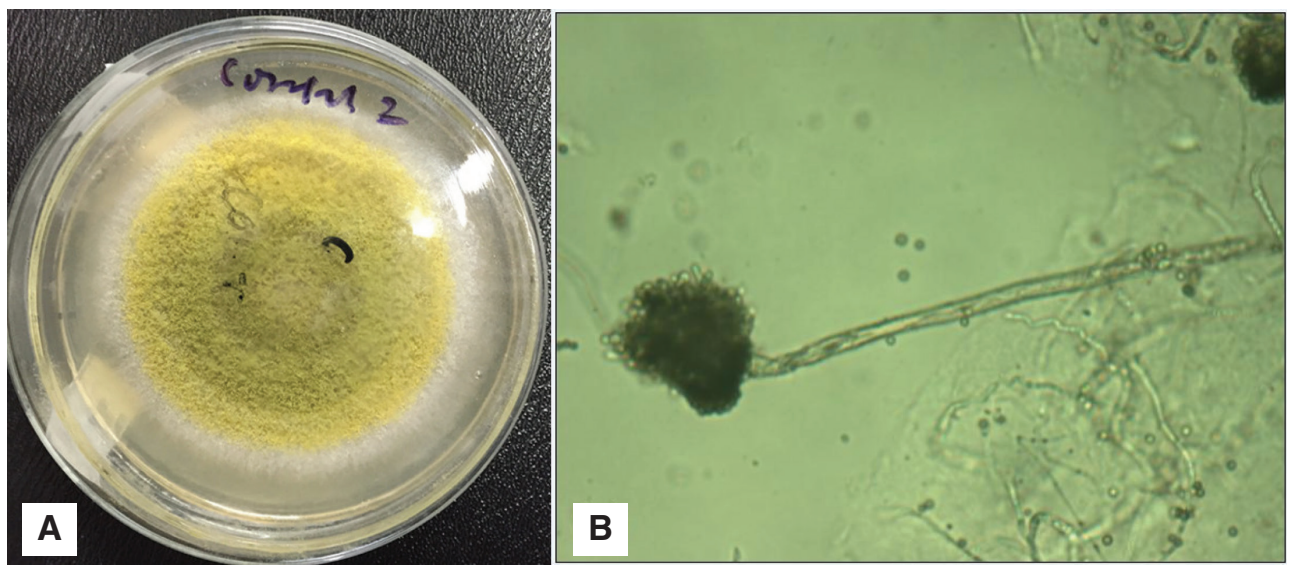

Figure 2: Mycellium and chain of its conidia in $B$. Colony (A) and cell morphology (B) of selected fungus.

fungal strain F3 was also determined. The ITS sequence size was $548 \mathrm{bps}$. According to the comparison in the Genbank databases, the result showed that the strain had $98 \%$ nucleotide base identity to A. flavus. The phylogenetic tree in Figure 3 shows the relationship between members of family Aspergillus and the strain F3. Therefore, on the basis of morphological and molecular biological results, strain F3 was identified as A. flavus.

\section{Heavy metal tolerance of $A$. flavus}

The growth function of heavy metals is inhibited by the reducing tolerance index (TI) (El-Sayed, 2015). The TI of A. flavus in the present study (Figure 4) demonstrated that different kinds of heavy metals posed different levels of toxicity to the growth of the strain. When the concentration of $\mathrm{Zn}^{+2}$ was less than $100 \mathrm{mg} \mathrm{L}^{-1}$, the TI was above 1.0, which means that $\mathrm{Zn}^{+2}$ with low concentration accelerated the growth of $A$. flavus that may be due to the fact that $Z^{+2}$ is one of the necessary trace elements required for microbial growth. When the concentration of $\mathrm{Zn}^{+2}$ and $\mathrm{Pb}$ were below $200 \mathrm{mg} \mathrm{L}^{-1}$ and $100 \mathrm{mg} \mathrm{L}^{-1}$ individually, TI was above 0.7, which indicated that the strain did not suffer too much inhibition on this scale of heavy metal concentrations. Additionally, when the concentrations of $\mathrm{Zn}^{+2}$ and $\mathrm{Pb}$ were up to $1000 \mathrm{mg} \mathrm{L}^{-1}$, the strain experienced significant growth on the plates, which was similar with the results reported by Iram et al., where for these heavy metals different concentration was used; e.g. for $\mathrm{Pb}$ it was $600 \mathrm{mg} / \mathrm{L}$ (Iram et al., 2013). However, as for Cd, TI reduced rapidly with the increase in concentration, and

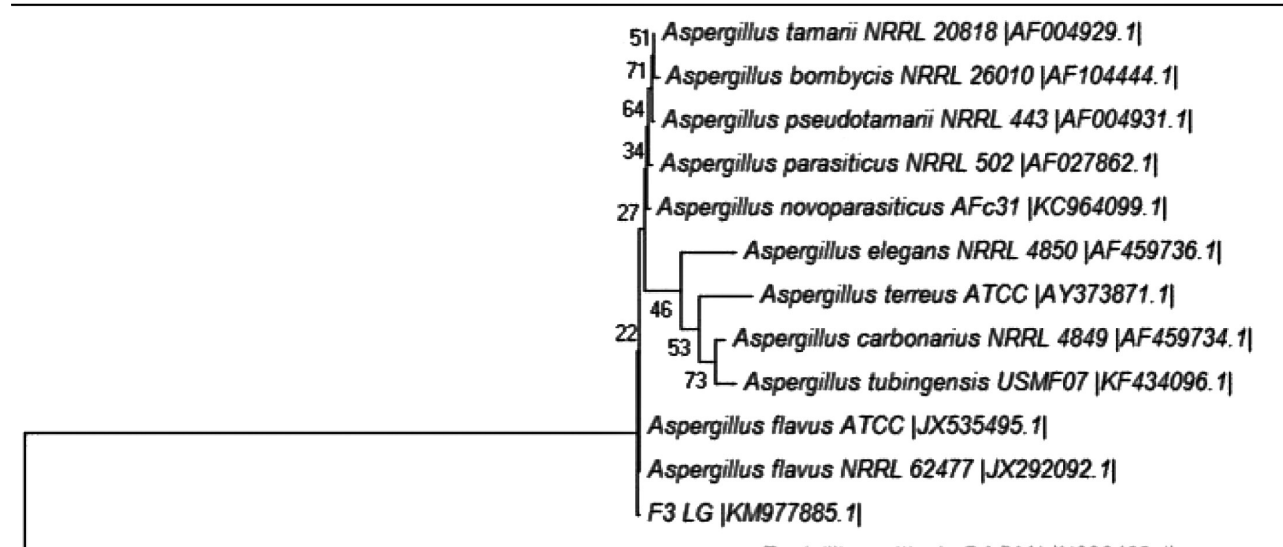

Penicillium viticola DAOM JNN686463.1|

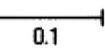

Figure 3: The phylogenetic tree of ITSs from all fungal isolates and other Aspergillus species relatives based on a maximum parsimony analysis of ITS sequences.

Penicillium viticola DAOM was used as outgroup. Phylogenetic tree was constructed by using Mega 5994.0 software. 


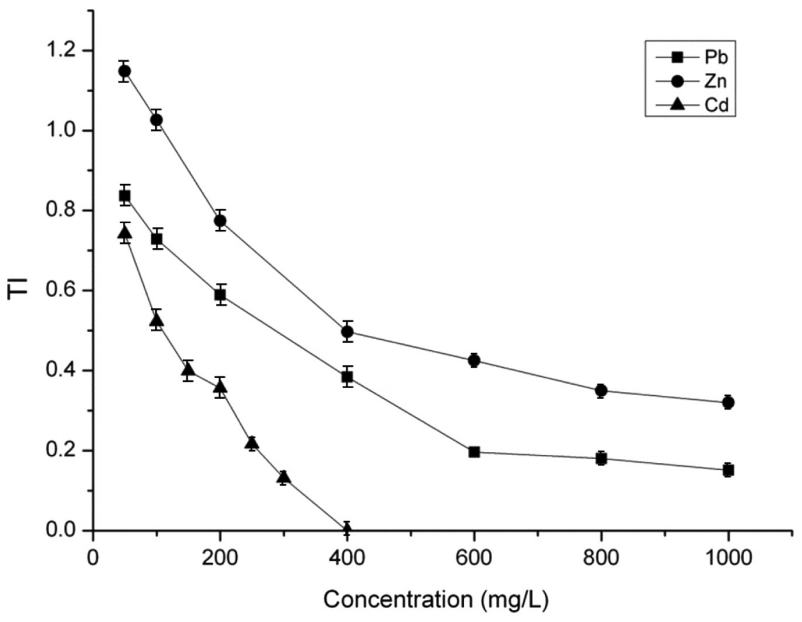

Figure 4: Tolerance index of $A$. flavus growing on SDA plates with heavy metals.

there was no visible growth when the concentration was up to $400 \mathrm{mg} \mathrm{L}^{-1}$. This may be due to stronger toxicity of $\mathrm{Cd}$ to microbes than other heavy metals (Baath, 1989).

\section{Bioleaching experiments}

\section{Influence of carbon sources on bioleaching efficiency}

Different carbon sources were selected for A. flavus to produce more organic acids. As shown in Figure 5, when glucose and sucrose were used as carbon sources, the bioleaching efficiency of $A$. flavus with sucrose as a carbon source was better than that with glucose (Daza et al., 2006). The result may be due to two reasons. Firstly, glucose can limit the secretion of malic acid to some extent as the main organic acid produced by A. flavus is malic acid. Secondly, the osmotic pressure of the bioleaching environment is maintained much better by sucrose than by glucose, which is beneficial for the growth and metabolism of A. flavus. Among the four concentrations for sucrose at $130 \mathrm{mg} \mathrm{L}^{-1}$, the leaching efficiencies of about $16.38 \%$ for $\mathrm{Pb}, 30.55 \%$ for $\mathrm{Cd}$ and $52.66 \%$ for $\mathrm{Zn}^{+2}$ were observed. On the other hand, when the sucrose content was $160 \mathrm{mg} \mathrm{L}^{-1}$, the leaching efficiencies were $19.65 \%$ for $\mathrm{Pb}, 20.47 \%$ for $\mathrm{Cd}$ and $54.78 \%$ for $\mathrm{Zn}^{+2}$. Considering the cost and bioleaching efficiency, $130 \mathrm{mg} \mathrm{L}^{-1}$ sucrose was thus recommended as the most suitable content for A. flavus in bioleaching for 15 days.

\section{Influence of $\mathrm{pH}$ on bioleaching efficiency}

Different $\mathrm{pH}$ values of sucrose medium were used to bioleach the heavy metals from contaminated soil.
Different $\mathrm{pH}$ values of 5, 5.71, 7 and 9 were selected to check the bioleaching efficiencies, while 5.71 is the natural $\mathrm{pH}$ of the sucrose medium. The bioleaching efficiencies are shown in Figure 6. At the $\mathrm{pH}$ value 7, the maximum leaching efficiencies were $18.16 \%$ for $\mathrm{Pb}, 39.77 \%$ for $\mathrm{Cd}$ and $58.22 \%$ for $\mathrm{Zn}^{+2}$. The order of bioleaching efficiencies of the three heavy metals at various $\mathrm{pH}$ values was different. For $\mathrm{Pb}$ and $\mathrm{Cd}$, the bioleaching efficiency at different $\mathrm{pH}$ values was in the order $\mathrm{pH} 7>\mathrm{pH} 5.71>\mathrm{pH} 5>\mathrm{pH}$ 9, while for $\mathrm{Zn}^{+2}$, the order was $\mathrm{pH} 7>\mathrm{pH} 5.71>\mathrm{pH} 9>\mathrm{pH} 5$. Overall, results showed that neutral solution is more suitable than alkaline solution and acidic solution for A. flavus to bioleach heavy metals from

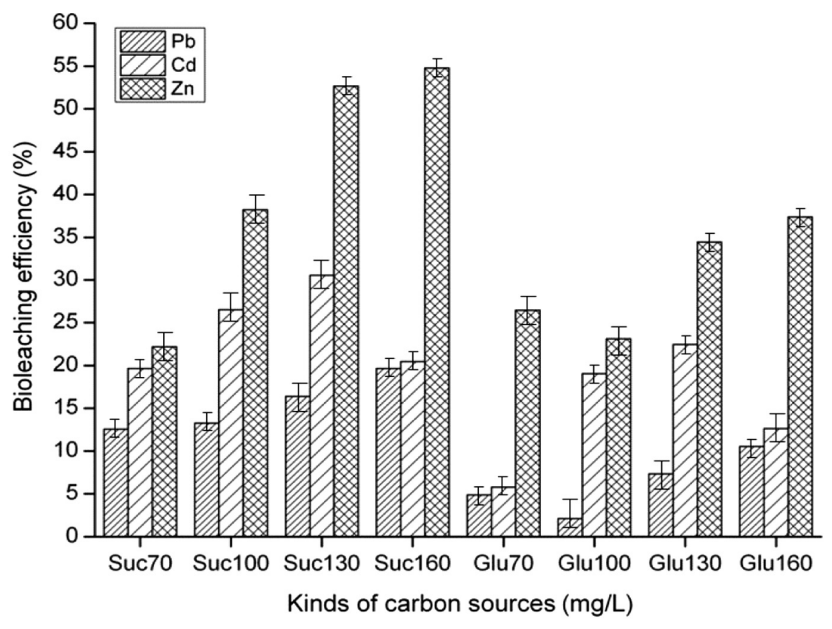

Figure 5: Bioleaching efficiencies of different carbon sources. Given values are the averages of triplicate samples; significant differences are shown by error bars in bioleaching, according to one-way ANOVA test at $p<0.05$.

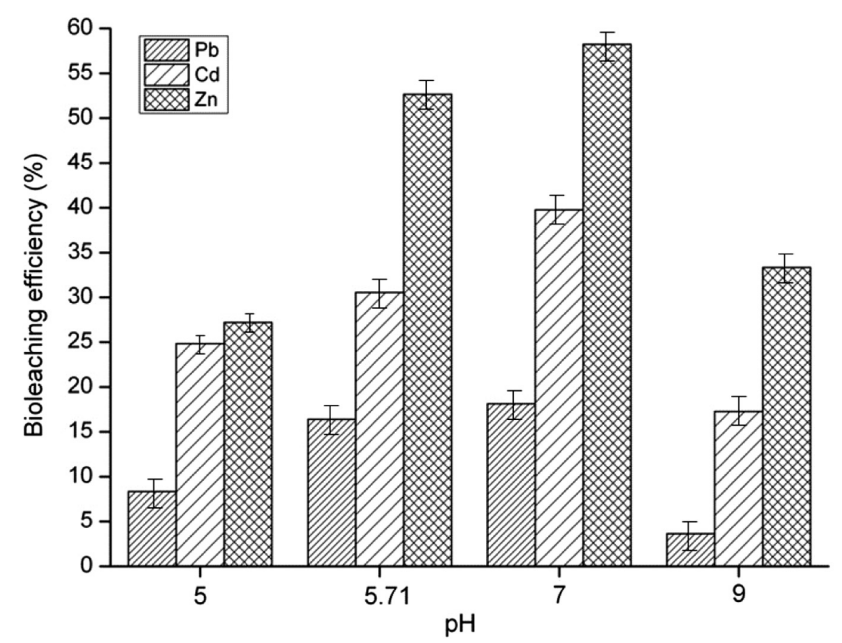

Figure 6: Bioleaching efficiencies of different $\mathrm{pH}$. Given values are the averages of triplicate samples; significant differences are shown by error bars in bioleaching, according to one-way ANOVA test at $p<0.05$. 
contaminated soil. Different $\mathrm{pH}$ environments affect the kinds and quantity of the metabolites that microbes produce (Chen and Lin, 2010). Neutral pH could promote the generation of organic acids by A. flavus (Battat et al., 1991).

\section{Influence of temperature on bioleaching efficiency} were larger than those at $20^{\circ} \mathrm{C}$ and $40^{\circ} \mathrm{C}$ (Figure 7). It was therefore concluded that $30^{\circ} \mathrm{C}$ is the most appropriate temperature for the growth and metabolisms of A. flavus. Therefore, many organic acids were produced at this temperature, and more heavy metals were leached from the contaminated soil. When the temperature is not suitable, the growth and enzymatic activities of microorganisms is limited especially when it is too high (Moat et al., 2003). The temperature of about $40^{\circ} \mathrm{C}$ resulted in biomass reduction of A. flavus as well as other Aspergillus genus, which was in line with other reports, so the bioleaching efficiencies of heavy metals at $40^{\circ} \mathrm{C}$ were the lowest.

\section{Comparison of different bioleaching methods}

Bioleaching efficiencies were compared in the onestep bioleaching with those in the two-step bioleaching (Figure 8). $\mathrm{Pb}$ showed approximate bioleaching efficiencies in both methods which were $18.16 \%$ in onestep bioleaching and $16.91 \%$ in two-step bioleaching, respectively. Bioleaching efficiencies of $\mathrm{Cd}$ and $\mathrm{Zn}^{2+}$ were
Bioleaching efficiencies of all the heavy metals at $30^{\circ} \mathrm{C}$

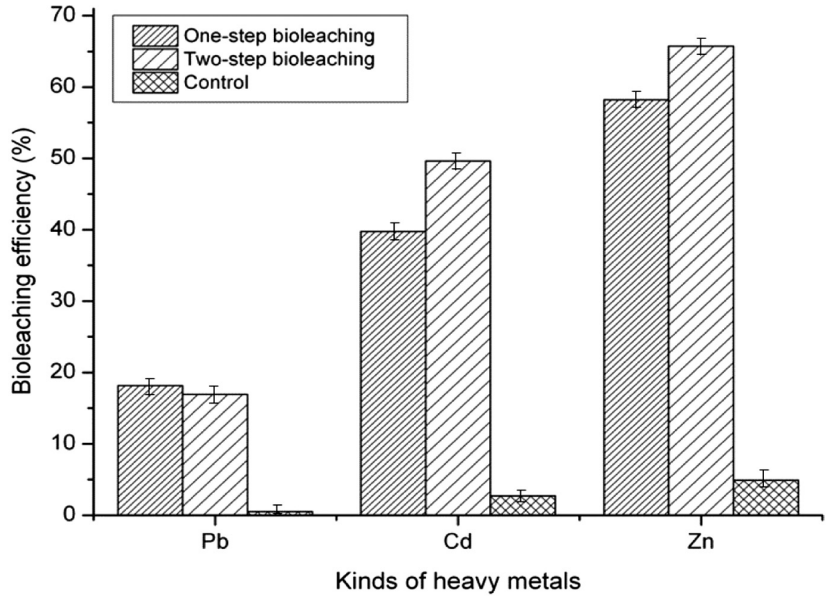

Figure 8: Bioleaching efficiencies of different methods. Given values are the averages of triplicate samples; significant differences are shown by error bars in bioleaching, according to one-way ANOVA test at $p<0.05$.

larger in two-step bioleaching than those in one-step bioleaching, 49.66\% for $\mathrm{Cd}$ and $65.73 \%$ for $\mathrm{Zn}^{2+}$ in twostep bioleaching but $39.77 \%$ for $\mathrm{Cd}$ and $58.22 \%$ for $\mathrm{Zn}^{2+}$ in one-step bioleaching. The reason may be due to the different types and quantities of organic acids produced by A. flavus at different bioleaching conditions (Bosshard et al., 1996). For both one-step and two-step bioleaching, the bioleaching efficiencies of heavy metals from soil was in a decreasing order $\mathrm{Zn}^{2+}>\mathrm{Cd}>\mathrm{Pb}$. Additionally, only a small amount of heavy metals were extracted in the control experiment.

\section{Conclusions}

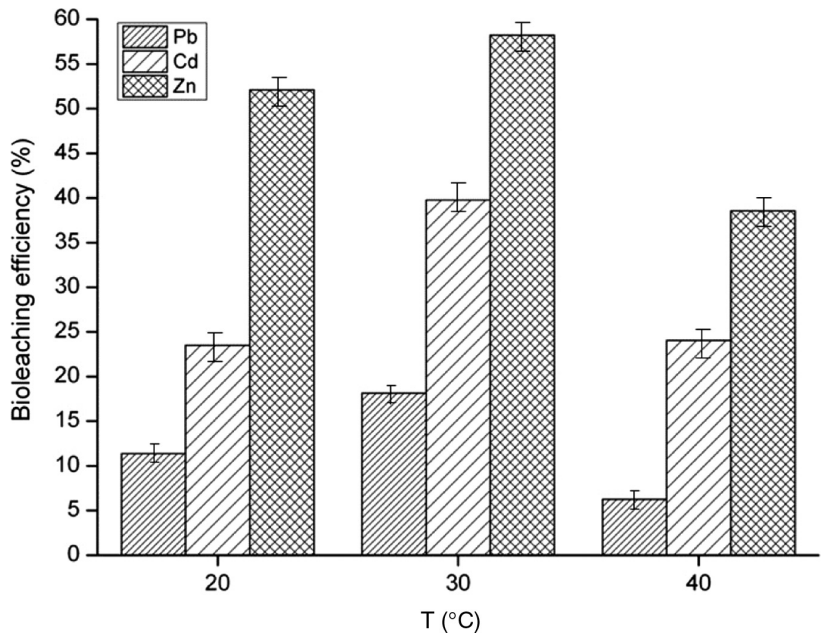

Figure 7: Bioleaching efficiencies of different temperatures. Given values are the averages of triplicate samples; significant differences are shown by error bars in bioleaching, according to one-way ANOVA test at $p<0.05$.
Aspergillus flavus is highly efficient for removal of heavy metals from contaminated soil. For bioleaching with A. flavus, sucrose as carbon source, $\mathrm{pH} 7$ and $30^{\circ} \mathrm{C}$ were the best conditions. Heavy metals removal from contaminated soil through bioleaching method is a practical technology. All the results show that $A$. flavus can be a good source for reducing toxicity of heavy metals from contaminated soil by implementing these optimizing conditions.

\section{Experimental}

\section{Soil characteristics}

The contaminated soil for the current study was collected from the top soil $(0-20 \mathrm{~cm})$ of a smelting industry site, located in Zhuzhou 
City, Hunan Province, China. The soil sample was dried in air, and a $2 \mathrm{~mm}$ sieve was used to avoid mixing of soil clumps, rocks and sundries. After sieving, homogeneity of the soil was ensured by mechanical mixing, and then the soil was kept in polythene bags before the experiment. An acid digestion method $\left(\mathrm{HNO}_{3}+\mathrm{HF}+\mathrm{HClO}_{4}\right)$ using an electric heating plate was performed to determine total heavy metal contents in the soil $(\mathrm{Lu}, 1999)$. The metal ions present in the digestive supernatant were analyzed using an atomic absorption spectrophotometer (AAS). The $\mathrm{pH}$ value of the soil was determined according to the method of potentiometric determination of solution $\mathrm{pH}$ value using a $\mathrm{pH}$-meter (soil:water $=1: 2.5$ ).

\section{Fungal isolation and screening}

To isolate the fungal strains used in the bioleaching experiments, 0.5 g soil was added to $50 \mathrm{~mL}$ sterile water and then shaken for $5 \mathrm{~h}$ at $30^{\circ} \mathrm{C}$ at $130 \mathrm{rpm}$. The supernatant was decanted and diluted into $10^{-3}-$ $10^{-7}$ dilution sequences. Some $0.1 \mathrm{~mL}$ of each dilution sequence was spread on Sabouraud Dextrose Agar (SDA) Merck (Darmstadt, Germany) plates containing $50 \mathrm{mg} \mathrm{L}^{-1} \mathrm{Cd}, 100 \mathrm{mg} \mathrm{L}^{-1} \mathrm{~Pb}$ and $100 \mathrm{mg} \mathrm{L}^{-1}$ $\mathrm{Zn}^{+2}$ individually. The composition of SDA medium is $10 \mathrm{~g} \mathrm{~L}^{-1}$ peptone, $40 \mathrm{~g} \mathrm{~L}^{-1}$ glucose and $20 \mathrm{~g} \mathrm{~L}^{-1}$ agar (Sigma-Aldrich, St. Louis, MO, USA). The plates were incubated at $30^{\circ} \mathrm{C}$ for $120 \mathrm{~h}$. Thereafter, the above isolated strains were purified and the mature spores were harvested from SDA surface individually using autoclaved deionized water. The number of spores was counted using a hemacytometer and standardized to about $1.0 \times 10^{7}$ spores $\mathrm{mL}^{-1}$. One milliliter of spore suspension was then added to $49 \mathrm{~mL}$ of sucrose medium with the following composition: $100 \mathrm{~g} \mathrm{~L}^{-1}$ sucrose, $1.5 \mathrm{~g} \mathrm{~L}^{-1} \mathrm{NaNO}_{3}, 0.5 \mathrm{~g} \mathrm{~L}^{-1} \mathrm{KH}_{2} \mathrm{PO}_{4}, 0.025 \mathrm{~g} \mathrm{~L}^{-1}$ $\mathrm{MgSO}_{4} \cdot 7 \mathrm{H}_{2} \mathrm{O}, 0.025 \mathrm{~g} \mathrm{~L}^{-1} \mathrm{KCl}$ and $1.6 \mathrm{~g} \mathrm{~L}^{-1}$ yeast extract. The $\mathrm{pH}$ values of all the liquid media were monitored every 2 days; the degradation of the $\mathrm{pH}$ values meant that many organic acids were produced during the oxidation of the sugar (Deng et al., 2012).

\section{Fungal identification}

The morphological observations of the selected fungus were performed as described by Domsch et al. (1993). The total genomic DNA of fungal isolates were isolated and purified by using the methods as explained by Zhu et al. (1994). The amplification and sequencing of ITS from the fungal strain were performed using primers ITS5: 5'-TCCGTAGGTGAACCTGCGG-3' and 5'-TCCTCCGCTTATTGATATGC-3'. In order to compare with currently available sequences, the sequences obtained above were aligned by using BLAST analysis (http://www. ncbi.nlm.nih.gov/BLAST). Sequences showing 98\% resemblance with currently accessible sequence were considered to belong to the same species. The ITS fragments inserted on the vector were sequenced by Genescript Company, Nanjing, China. Furthermore, multiple alignments were performed using Clustal X 1.83, and MEGA 4.0 was used for the construction of the phylogenetic tree (Tamura et al., 2007).

\section{Heavy metal tolerance of $A$. flavus}

To determine the TI of $A$. flavus, SDA medium was enriched with increasing concentrations of $\mathrm{Cd}(0,50,100,150,200,250,300$ and $\left.400 \mathrm{mg} \mathrm{L}^{-1}\right), \mathrm{Pb}\left(0,50,100,200,400,600,800\right.$ and $\left.1000 \mathrm{mg} \mathrm{L}^{-1}\right)$ and $\mathrm{Zn}^{2+}\left(0,50,100,200,400,600,800\right.$ and $\left.1000 \mathrm{mg} \mathrm{L}^{-1}\right)$, respectively. Some $0.5 \mu \mathrm{L}$ of spore suspension was added into SDA plates and cultivated at $30^{\circ} \mathrm{C}$ for 6 days in an incubator. The growth of A. flavus was observed by measuring diameters of colonies using crossing method (Amiri et al., 2011). TI, an indication of the organism response to metal stress, was calculated from the growth of strain exposed to the metals divided by the growth in the control on the sixth day.

\section{Optimization conditions for bioleaching experiments}

Selection of carbon source: The carbon source is the chief nutrient that fungi demand (Walid et al., 2007). Different kinds and contents of carbon sources have a crucial role in the life activities and metabolisms of fungi (Qu et al., 2013). In this study, different sucrose and glucose were employed. The concentrations were 70, 100, 130 and $160 \mathrm{~g} \mathrm{~L}^{-1}$ in modified sucrose medium individually. Forty-nine milliliters of liquid medium was added into $250 \mathrm{~mL}$ sterile conical flask with 5\% (w/v) sterile soil for bioleaching. One milliliter of A. flavus spore suspension (about $1.0 \times 10^{7}$ spores $\mathrm{mL}^{-1}$ ) was added aseptically to each flask. All the cultures were agitated at $30^{\circ} \mathrm{C}$ at $130 \mathrm{rpm}$ in a rotary shaking incubator for 15 days. Samples of each conical flask were centrifuged at $5000 \mathrm{rpm}$ and then filtered through a $0.45 \mu \mathrm{m}$ membrane. The filtrates were analyzed for heavy metal concentration. Sterile deionized water was supplemented every 3 days to keep the mass balance of each flask. All experiments were run in triplicate.

Sterile experimental conditions were achieved by autoclaving all the flasks containing modified sucrose medium at $121^{\circ} \mathrm{C}$ for $20 \mathrm{~min}$ prior to inoculation; the polluted soil was autoclaved separately.

Selection of $\mathrm{pH}$ : Different $\mathrm{pH}$ values were employed in bioleaching methods. One milliliter of spore suspension was inoculated into $250 \mathrm{~mL}$ autoclaved flask containing $49 \mathrm{~mL}$ sucrose medium and $5 \%(\mathrm{w} / \mathrm{v})$ autoclaved soil. The $\mathrm{pH}$ values of the above medium was adjusted to 5, 5.7 (natural $\mathrm{pH}$ of the medium), 7 and 9 by using $0.1 \mathrm{~mol} \mathrm{~L}^{-1} \mathrm{HCl}$ and $0.1 \mathrm{~mol} \mathrm{~L}^{-1} \mathrm{NaOH}$. The method of bioleaching process was the same as described in 'Influence of carbon sources on bioleaching efficiency' section. The bioleaching efficiencies of different $\mathrm{pH}$ values were compared by determining $\mathrm{Pb}, \mathrm{Zn}^{2+}$ and $\mathrm{Cd}$ concentrations in filtrates. Each $\mathrm{pH}$ value level was run in triplicate.

Selection of temperature: Soil was bioleached using the same liquid medium as mentioned above at 20,30 and $40^{\circ} \mathrm{C}$. The efficiencies of bioleaching at different temperatures were compared by determining the metal concentrations in filtrates using AAS. Each temperature level was run in triplicate.

One-step and two-step bioleaching: Two methods of bioleaching were performed which were named as one-step and two-step bioleaching. In one-step bioleaching, the fungus was incubated together with the medium and sterile soil in a rotary shaking incubator for 15 days. In two-step bioleaching, pure culture of the fungus was run for 6 days, and then the autoclaved soil was added; bioleaching experiment was performed in a rotary shaker for 9 days. A control experiment was also carried out in parallel without inoculation. All the experiments were run in triplicate. 
Statistical analysis: To compare the difference of methods, one-way ANOVA at $p<0.05$ level of significance was applied by using least significant difference test in SPSS 16 software (SPSS, Inc.). Each method was performed in triplicate.

Acknowledgments: This work was supported by the State Key Laboratory of Environmental Criteria and Risk Assessment (No. SKLECRA2013FP12) and the Public Science and Technology Research Funds Projects of Ocean, China (201105020).

\section{References}

Amiri, F.; Yaghmae, I. S.; Mousavi, M. Bioleaching of tungsten-rich spent hydrocracking catalyst using Penicillium simplicissimum. Bioresource Technol. 2011, 102, 1567-1573.

Baath, E. Effects of heavy metals in soil on microbial processes and populations (a review). Water Air Soil Poll. 1989, 47, 335-379.

Battat, E.; Peleg, Y.; Bercovitz, A.; Rokem, J. S.; Goldberg, I. Optimization of L-malic acid production by Aspergillus flavus in a stirred fermentor. Biotechnol. Bioeng. 1991, 37, 1108-1116.

Bosshard, P. B.; Bachafen, R.; Brandl, H. Metal leaching of fly ash from municipal waste incineration by Aspergillus niger. Environ. Sci. Technol. 1996, 30, 3066-3077.

Chen, Y.; Lin, L. Optimization of operating parameters for the metal bioleaching process of contaminated soil. Sep. Purif. Technol. 2010, 71, 178-185.

Daza, A.; Manjon, J. L.; Camacho, M.; Romero de la Osa, L.; Aguilar, A.; Santmaria, C. Effect of carbon and nitrogen sources, $\mathrm{pH}$ and temperature on in vitro cultures of several isolates of Amanita caesarea (Scop.:Fr.) Pers. Mycorrhiza 2006, 16, 133-136.

Deng, X.; Chai, L.; Yang, Z.; Tang, C.; Tong, H.; Yuan, P. Bioleaching of heavy metals from a contaminated soil using indigenous Penicillium chrysogenum strain F1. J. Hazard. Mater. 2012, 233, 25-32.

Domsch, K. H.; Gams, W.; Erson, T. Compedium of Soil Fungi; Academic Press: London, UK, 1993; Vol. 2.

Dowdy, R. H.; Volk, V. Movement of heavy metals in soils. Chem. Mobil. Reactiv. Soil Syst. Chemicalmobilit. 1983, 4, 229-240.

El-Sayed, M. T. An investigation on tolerance and biosorption potential of Aspergillus awamori ZU JQ 965830.1 to Cd (II). Ann. Microbiol. 2015, 65, 69-83.

Gilbert, R.; Wey, T. E. Nonmetallic abrasive blasting material recovery process including an electrostatic separation step: U.S. Patent. 1990, 4,943,368, 7-24.

Govarthanan, M.; Lee, G. W.; Park, J. H.; Kim, J. S.; Lim, S. S.; Seo, S. K.; Cho, M.; Myung, H.; Kamala-Kannan, S.; Oh, B. T. Bioleaching characteristics, influencing factors of $\mathrm{Cu}$ solubilization and survival of Herbaspirillum sp. GW103 in Cu contaminated mine soil. Chemosphere 2014, 109, 42-48.

Hong, P. K.; Li, C.; Banerji, S. K.; Regmi, T. Extraction, recovery, and biostability of EDTA for remediation of heavy metal-contaminated soil. J. Soil Contam. 1999, 8, 81-103.

Iram, S.; Zaman, A.; Iqbal, Z.; Shabbir, R. Heavy metal tolerance of fungus isolated from soil contaminated with sewage and industrial wastewater. Pol. J. Environ. Stud. 2013, 22, 691-697.
Ko, M. S.; Park, H. S.; Kim, K. W.; Lee, J. U. The role of Acidithiobacillus ferrooxidans and Acidithiobacillus thiooxidans in arsenic bioleaching from soil. Environ. Geochem. Health 2013, 5 , 727-733.

Kurniati, E.; Arfarita, N.; Imai, T.; Higuchi, T.; Kanno, A.; Yamamoto, K.; Sekine, M. Potential bioremediation of mercury-contaminated substrate using filamentous fungi isolated from forest soil. J. Environ. Sci. 2014, 26, 1223-1231.

Leštan, D.; Luo, C.; Li, X. The use of chelating agents in the remediation of metal-contaminated soils: a review. Environ. Pollut. 2008, 153, 3-13.

Lu, R. K. Soil Agriculture Chemistry Analysis Method; Agriculture Science Press of China: Beijing, China, 1999.

Moat, A. G.; Foster, J. W.; Spector, M. P. Microbial Physiology; John Wiley \& Sons: Hoboken, NJ, USA, 2003.

More, T. T.; Yan, S.; Tyagi, R. D.; Surampalli, R. Y. Potential use of filamentous fungi for wastewater sludge treatment. Bioresource Technol. 2010, 101, 7691-7700.

Mulligan, C.; Cloutier, G. Bioremediation of metal contamination. Environ. Monit. Assess. 2003, 84, 45-60.

Ok, Y. S.; Kim, S. C.; Kim, D. K.; Skousen, J. G.; Lee, J. S.; Cheong, Y. W.; Kim, S. J.; Yang, J. E. Ameliorants to immobilize Cd in rice paddy soils contaminated by abandoned metal mines in Korea. Environ. Geochem. Health 2011, 33, 23-30.

Qayyum, S.; Khan, I.; Maqbool, F.; Zhao, Y.; Gu, Q.; Peng, C. Isolation and characterization of heavy metal resistant fungal isolates from industrial soil in China. Pak. J. Zool. 2016, 48, 1241-1247.

Qu, Y.; Lian, B.; Mo, B.; Liu, C. Bioleaching of heavy metals from red mud using Aspergillus niger. Hydrometallurgy 2013, 136, 71-77.

Rasime, D.; Nalan, Y.; Sariozlu, S. İ. Polymerase chain reaction (PCR) identification of terverticillate penicillium species isolated from agricultural soils in eskişehir province. Braz. Arch. Biol. Technol. 2013, 56, 980-984.

Rebele, F.; Lehmann, C. Phytoextraction of cadmium and phytostabilisation with mugwort (Artemisia vulgaris). Water Air Soil Poll. 2011, 216, 93-103.

Ren, W.; Li, J.; Geng, Y.; Li, X. J. Biological leaching of heavy metals from a contaminated soil by Aspergillus niger. J. Hazard. Mater. 2009, 167, 164-169.

Tamura, K.; Dudley, J.; Nei, M.; Kumar, S. MEGA4: molecular evolutionary genetics analysis (MEGA) software version 4.0. Mol. Biol. Evol. 2007, 24, 1596-1599.

Valix, M.; Usai, F.; Malik, R. Fungal bioleaching of low grade laterite ores. Miner. Eng. 2001, 14, 197-203.

Vega, F. A.; Covelo, E. F.; Andrade, M. L.; Marcet, P. Relationships between heavy metals content and soil properties in minesoil. Anal. Chim. Acta 1994, 524, 141-150.

Walid, A.; Ghanem, K. M.; Ehab, R. E. H. Citric acid production by a novel Aspergillus niger isolate: I. Mutagenesis and cost reduction studies. Bioresource Technol. 2007, 98, 3464-3469.

Walker, D. J.; Clemente, R.; Roig, A.; Bernal, M. P. The effects of soil amendments on heavy metal bioavailability in two contaminated Mediterranean soils. Environ. Pollut. 2003, 122, 303-312.

Wang, X.; Ma, X. Advances in the research of phytoremediation in heavy metal contaminated soils. Subtrop. Agric. Res. 2008, 1, 011.

Zhu, H.; Qu, F.; Zhu, L. Extracting fungi DNA for molecular biology analysis using $\mathrm{CHCl}_{3}$. Acta Mycol. Sin. 1994, 13, 34-40. 